\title{
Comparative Analysis of Movement Intensities in Student Using Polar Global Positioning System (GPS): A Pilot Study in Physical Education Learning
}

\author{
Lutfi Nur ${ }^{1, *}$, Arief Abdul Malik², Didik Rilastiyo Budi ${ }^{3}$, Muchamad Arif Al Ardha ${ }^{4}$ \\ ${ }^{1}$ Department of Elementary Teacher Education, Tasikmalaya Campus, Universitas Pendidikan Indonesia, Bandung, 40154, Indonesia \\ ${ }^{2}$ Department of Physical Education, Faculty of Teacher Training and Education, Universitas Siliwangi, Tasikmalaya, 46115, Indonesia \\ ${ }^{3}$ Department of Physical Education, Faculty of Health Sciences, Universitas Jenderal Soedirman, Purwokerto, 53123, Indonesia \\ ${ }^{4}$ Department of Physical Education and Kinesiology, Huang Shih College of Education, National Dong Hwa University, 974301, \\ Taiwan \\ *Corresponding Author: lutfinur@upi.edu
}

Received December 18, 2020; Revised January 18, 2021; Accepted February 24, 2021

\section{Cite This Paper in the following Citation Styles}

(a): [1] Lutfi Nur, Arief Abdul Malik, Didik Rilastiyo Budi, Muchamad Arif Al Ardha , "Comparative Analysis of Movement Intensities in Student Using Polar Global Positioning System (GPS): A Pilot Study in Physical Education Learning," International Journal of Human Movement and Sports Sciences, Vol. 9, No. 2, pp. 203-208, 2021. DOI: 10.13189/saj.2021.090206.

(b): Lutfi Nur, Arief Abdul Malik, Didik Rilastiyo Budi, Muchamad Arif Al Ardha (2021). Comparative Analysis of Movement Intensities in Student Using Polar Global Positioning System (GPS): A Pilot Study in Physical Education Learning. International Journal of Human Movement and Sports Sciences, 9(2), 203-208. DOI: 10.13189/saj.2021.090206.

Copyright $\bigcirc 2021$ by authors, all rights reserved. Authors agree that this article remains permanently open access under the terms of the Creative Commons Attribution License 4.0 International License

\begin{abstract}
This research is a pilot study aimed at analyzing the intensity of male and female students' learning movement comparison using a polar global positioning system (GPS). It is a comparative study, and participants in this study were junior high school students aged 12-13 years, totaling eight students (four males and four females). The research instruments used were Polar GPS RC3 and Polar Heart Rate Sensor H3 to measure the distance and heart rate of students during the learning process. All participants were given a tactical learning model and a technical learning model on different physical education learning days. After that, they were analyzed comparatively to find out the difference. The results showed differences in the intensity of movement in male and female students, with the tactical learning group had higher intensity of movement. Besides, the average male students had higher movement intensity than female students. This study's findings could be used as evaluation material for teachers to improve the physical education teaching and learning process quality. Furthermore, the use of technology, such as the Polar Global Positioning System (GPS), helps teachers monitor their students' level of physical activity. Since this research is a pilot study,
\end{abstract}

further research is needed to determine the differences between the two learning models and gender-based student movement intensity more comprehensively. Besides, the comparison of giving feedback during the lesson is also suggested for further research.

Keywords Movement, Gender, Physical Education, Polar GPS

\section{Introduction}

The era of the industrial revolution 4.0 provides a new order in human life. The emergence of technological breakthroughs provides various kinds of convenience in human life, including health and sports, as they can be applied in assisting educational evaluation [1]-[3]. Health is an essential investment so that we, as humans, should always try to be productive. Recently, the global world faces the threat of degenerative diseases such as diabetes caused by decreased movement and low awareness of exercise. It does not fulfill the average daily movement 
suggested [4]-[7]. Children and adolescents aged 5-17 years should spend at least 60 minutes, cumulatively, at moderate to vigorous levels of physical activity daily [8], [9]. Other studies have shown that moderate to vigorous physical activity intensity is associated with total and nervous adiposity after controlling total activity volume [10], [11]. Health organizations recommend that children and adolescents be encouraged to join in moderate to vigorous physical activity [9], [12]. The population at high risk is adult women in Asia because they have less physical activity patterns and poor diet and sleep patterns [13]. For women, this unhealthy behavior occurs during a critical development period. This behavior can last for years until they give birth, leading to overweight or fat accumulation [14].

In the world of education, physical education is an essential part of achieving educational goals. Physical education can have a significant impact on the physical activities of the younger generation if learning materials are planned and applied referring to moderate to vigorous physical activity (MVPA) [15]. This kind of activity can be realized through providing variations in physical movements and applying learning models that show the influence of contextual and pedagogical factors (teaching and learning, learning objectives, learning materials, environment, and teaching styles) in male students and female students [16]. Furthermore, other studies suggest that physical education contributes to total physical activity, especially in the category of higher intensity physical activity [17]. Therefore, in the learning process, the teacher must strive to design physical education learning that meets the moderate intensity of movement to fulfill one of the requirements for achieving minimal fitness by increasing movement activity. Besides, physical instructors become the key to achieving physical fitness and a good understanding of physical activity and movement activities for the younger generation. These instructors not only act as examples for the younger generation, but they are also placed to encourage physical activities outside of school, facilitate students to become independent individuals and provide initiatives to the broader community [18].

The intensity of movement in physical activity can be determined through the average heart rate per minute, which can practically be determined by measuring the wrist's pulse. Currently, the use of polar technology can provide a useful and objective picture of the heart rate. The most recent trend to measure physical fitness goals in schools is to use data from accelerometers on an ongoing basis [19], [20]. This trend is essential for researchers and policymakers in the future to recognize the school environment as a means for changing the physical activity level of female students by emphasizing multicomponent interventions theoretically [21].

Polar GPS technology can help measure the heart rate, distance covered, and the number of calories burned during physical activity. One of the advantages is that heart rate data can be measured objectively and digitally recorded, making it easier for teachers and coaches to measure how the quality and quantity of movement performed [22], [23]. In physical education learning, this tool is recommended to help teachers evaluate the learning and as information for teachers to improve the quality of learning [19]. However, there have not been many studies conducted comparing male and female students' movement activities using polar GPS when doing physical education learning activities. Therefore, this study aimed to analyze the comparative picture of the intensity of movement in male and female students using a polar global positioning system (GPS).

\section{Materials and Methods}

A comparative study was used to determine differences in movement intensity during physical education learning in junior high school students. Eight students (four males and four females) aged 12-13 years were involved in this study. All participants took part in physical education learning using technical learning models and tactical learning models at two different times with 80 minutes for each lesson: 15 minutes of preliminary activities, 50 minutes of core activities, and 15 minutes of closing activities. There were two research instruments used in this research. The first one was Polar GPS RC3, which was used to measure students' position and movement. Meanwhile, the Polar Heart Rate Sensor H3 was used on the chest to determine the heart rate [23], [24]. All measurement data was integrated with the polarpersonaltrainer.com web. The data from the web were then analyzed by comparing the average data acquisition for each test item.

\section{Result}

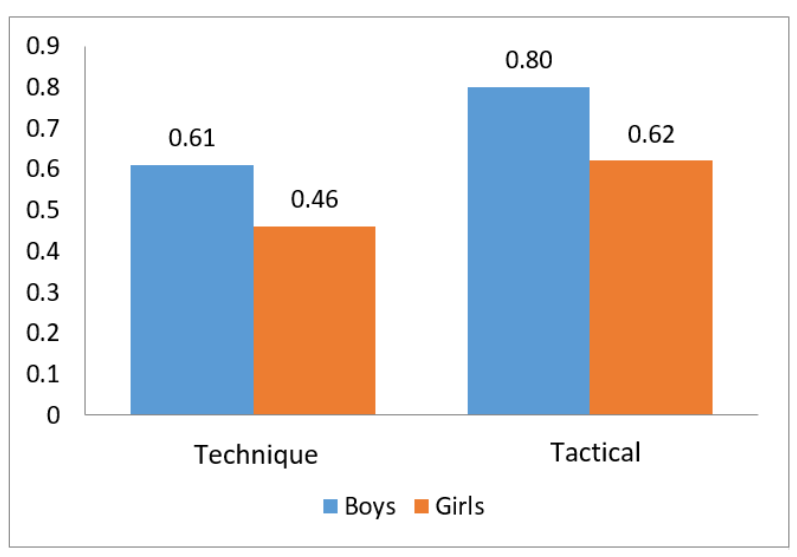

Figure 1. The distance covered by the student, km 
Figure 1 shows the distance that the students travelled during learning activities. In the male group with the technical learning approach, the distance covered was $0.61 \mathrm{~km}$, while in the male group with the tactical learning approach; the distance was farther, $0.8 \mathrm{~km}$. The distance covered by the female's group using the technical learning approach was $0.46 \mathrm{~km}$, while the female's group using the tactical learning approach, the distance covered was 0.62 $\mathrm{km}$.

Figure 2 shows the students' average heart rate when warming-up for 10 minutes. The average heart rate for male students in the technical group was $139 \mathrm{bpm}$, while the tactical group was $147.75 \mathrm{bpm}$. For female students in the technical group, the average heart rate was $127 \mathrm{bpm}$. While in the tactical group, it was $135.25 \mathrm{bpm}$.

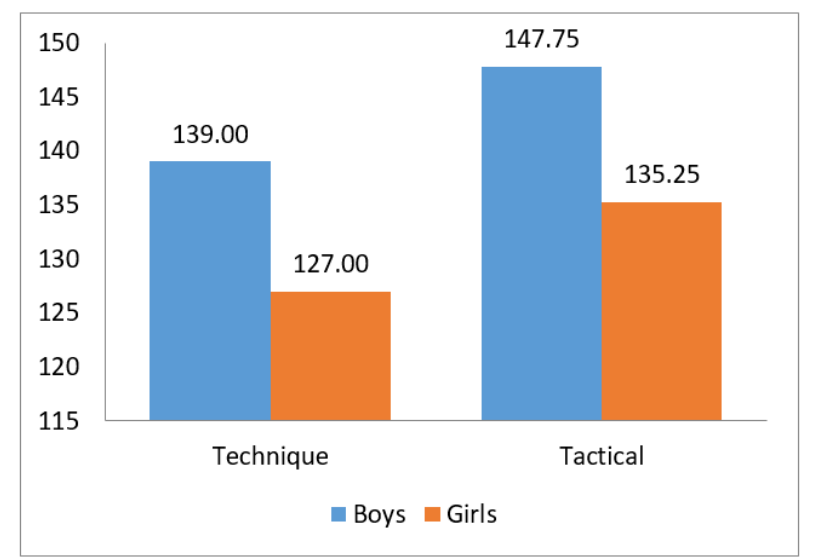

Figure 2. Heart Rate in Tactical and Technical Groups during Warming-up, bpm

Figure 3 shows the average heart rate during core learning activities. The heart rate for male students in the technical learning approach group was $127.50 \mathrm{bpm}$, while the tactical learning approach group was $155 \mathrm{bpm}$. Female students' heart rate in the technical learning approach group was $127.39 \mathrm{bpm}$, while in the tactical learning approach group was $140 \mathrm{bpm}$.

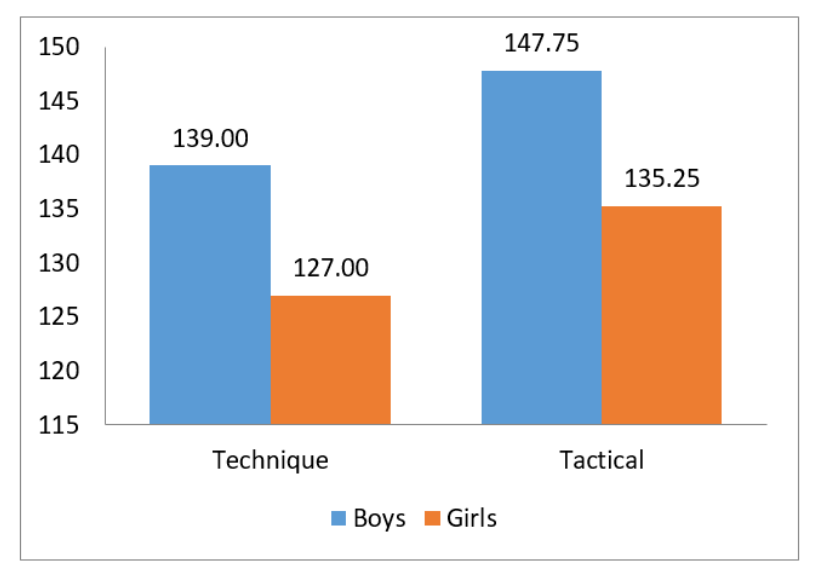

Figure 3. The Average Heart Rate during the Core Learning Activities, bpm
Figure 4 shows that male students' heart rate from warming-up activities to core activities in the technical learning approach group experienced a significant decrease. In the warming-up stage, male students' heart rates were at an average of $139 \mathrm{bpm}$. Meanwhile, at the core activity stage of learning, male students' heart rate decreased to $127.5 \mathrm{bpm}$. In female students, the heart rate in warming-up activity was at $127 \mathrm{bpm}$ and was relatively constant until the core stage of learning with $127.39 \mathrm{bpm}$.

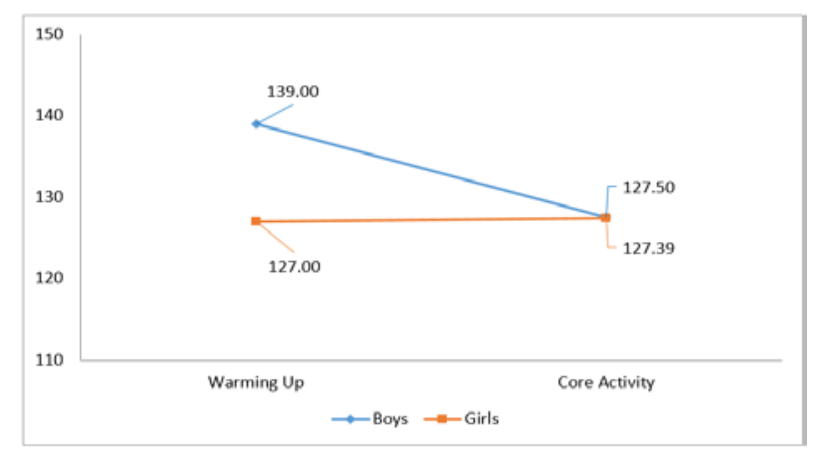

Figure 4. The Heart Rate of Warming-up and Core Activities in the Technical Learning Approach Group, bpm

Figure 5 shows students' heart rate in warming-up activities and core activities in the tactical learning approach group. The heart rate of male students in warming-up to core activities had increased. During the warming-up, male students had an average heart rate of $147.75 \mathrm{bpm}$. In the core activity of learning, the average heart rate was $155 \mathrm{bpm}$. The average heart rate in female students also increased from $135.25 \mathrm{bpm}$ in warming-up activities up to $140 \mathrm{bpm}$ in core activities.

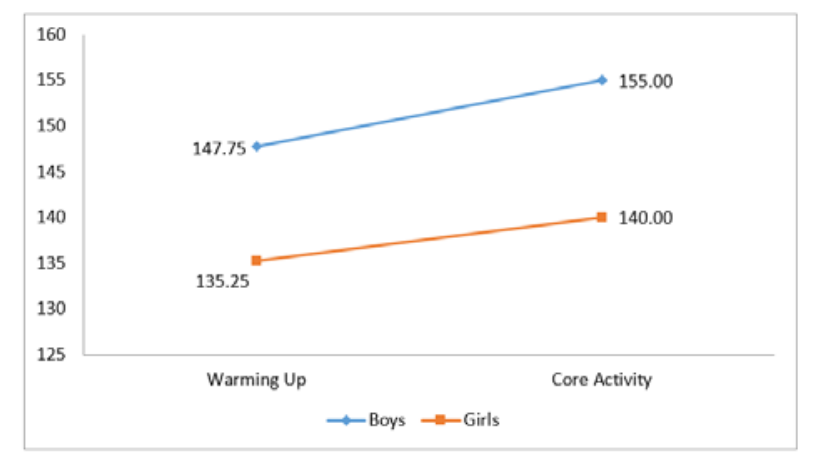

Figure 5. The Heart Rate of Warming-up and Core Activities in the Tactical Learning Approach Group, bpm.

Table 1 shows the difference in heart rates based on gender and learning approaches. The data were processed through a multivariate test with Wilks' Lambda analysis.

Table 1 shows that there is a difference in heart rate in each group based on gender $(\mathrm{p}<0.025)$ and differences in both tactical and technical learning approaches ( $\mathrm{p}<0.001$ ). Meanwhile, when viewed from gender and learning approach to heart rate, there is no significant difference ( $\mathrm{p}>$ 0.285 ). 
Table 1. Comparison of Movement Intensity based on Gender and Learning Approach

\begin{tabular}{|c|c|c|c|c|c|c|}
\hline Effect & Value & $\mathrm{F}$ & Hypothesis df & Error df & Sig. & Partial Eta Squared \\
\hline Intercept & .003 & $7.828 \mathrm{E}^{\mathrm{a}}$ & 4.000 & 9.000 & .000 & .997 \\
\hline Approach & .151 & $12.675^{\mathrm{a}}$ & 4.000 & 9.000 & .001 & .849 \\
\hline Gender & .322 & $4.737^{\mathrm{a}}$ & 4.000 & 9.000 & .025 & .678 \\
\hline Approach* Gender & .603 & $1.484^{\mathrm{a}}$ & 4.000 & 9.000 & .285 & .397 \\
\hline
\end{tabular}

\section{Discussion}

This research is a pilot study aimed to analyze the comparative picture of the intensity of movement in male and female students by applying technical learning models and tactical learning models in physical education learning in junior high school students using a polar Global Positioning System (GPS).

In the results of the distance the students covered during physical education learning, it was seen that male students were more active than female students in all learning models. This result can be seen from the difference in the average distance covered. However, the exciting thing is that when female students applied the tactical learning model, they got a slightly larger distance than male students who used the technical learning model. It means that the type of learning model applied has an impact on the distance covered by students. This fact is consistent with previous research, suggesting that students showed higher levels of physical activity (MVPA) during rugby and football games and were more motivated through tactical models than direct instruction models [16] Hence, the tactical learning model can positively contribute to increasing learning motivation and the intensity of student movement in physical education learning. Supporting the findings of this study, the results of other studies also revealed that the tactical learning model was superior to the technical learning model in developing motivation [25]-[27], improved performance in women's football games [28], general football performances [29], [30], performance and decision making in invasion games [31], technical skills, understood how to play, and performance in field hockey [32]. Meanwhile, through technical learning, several studies have shown that learning could improve sports branches' fundamental technical skills [16], [33]. However, in this study, the repeated application of the assignment model for fundamental technical skills exercises showed that students felt bored and bored, even though they showed enthusiasm in carrying out their movement tasks in the early stages.

The intensity of movement is students' ability to carry out physical activities to gain better understanding, knowledge, and behavior through training procedures and experiences [34]. The intensity of the movement referred to in this study includes two things: the heart rate and the distance covered in each physical education learning process. The study results support the relationship between the learning approach and the high and low intensity of movement intensity. Measurement through polar shows objective and transparent results. This measurement can determine the average heart rate per minute and the maximum heart rate in students during physical activity warm-up to core activity. Another study measuring fundamental movement skills concerning physical activity on weekdays and weekends in preschool children using accelerometers showed that boys were more active than girls and had higher object control competency skills seen in total skills score, which was positively associated with weekend moderate-to-vigorous physical activity but not weekday physical activity categories [35].

Several studies have confirmed that psychological health benefits are near related to physical fitness. In particular, the state of neuroticism does not affect a person's depression, especially for those with higher levels of cardiorespiratory fitness (CRF). Thus, promoting physical fitness to adolescents or adults with high neuroticism levels is necessary [36]. Besides, one study revealed that physical activity is fun for teenage girls both socially and physically. This study also contributes to the literature by identifying several factors in the social and physical environment associated with physical fitness and pleasurable activities [37]. In the context of gender, the results of other studies indicate that female students are more interested in modern physical learning which is not included in the school program while male students prefer sports games [38]. Furthermore, with regard to physical exercise in handball, the performances of males in total reaction time were significantly higher than females, but no significant differences were noted in speed of treatment information and visual perception time. It was suggested that physical activity could be used as a means of stimulating cognitive skills and developing student training programs to optimize specific cognitive functions and enhance learning [39].

\section{Conclusions}

Technology such as GPS can make it easier for teachers and coaches to evaluate learning outcomes and athletes' training results. This study concluded that the movement intensity of male and female students in the tactical learning group, starting from the warming-up process to the core of learning, experienced a significant increase. 
Whereas in the technical learning group, male students' movement intensity decreased sharply, but in female students, it was relatively constant. The teacher's role in designing learning using an approach and developing learning content to optimize motivation, space and intensity of movement is essential in fulfilling moderate physical activity. Since this research is a pilot study, further research is needed with larger sample sizes and various learning models to find a more comprehensive difference.

\section{REFERENCES}

[1] M. M. Alam and E. Ben Hamida, "Surveying wearable human assistive technology for life and safety critical applications: Standards, challenges and opportunities," Sensors, vol. 14, no. 5, pp. 9153-9209, 2014. doi: $10.3390 / \mathrm{s} 140509153$

[2] J. Lee, D. Kim, H.-Y. Ryoo, and B.-S. Shin, "Sustainable wearables: Wearable technology for enhancing the quality of human life," Sustainability, vol. 8, no. 5, p. 466, 2016. doi: 10.3390/su8050466

[3] L. Nur, L. A. Nurani, D. Suryana, and A. Ahmad, "Rasch model application on character development instrument for elementary school students,” International Journal of Learning, Teaching and Educational Research, vol. 19, no. 3, pp. 437-459, 2020. doi: 10.26803/ijlter.19.3.24

[4] S. Carbone, M. G. Del Buono, C. Ozemek, and C. J. Lavie, "Obesity, risk of diabetes and role of physical activity, exercise training and cardiorespiratory fitness.," Progress in Cardiovascular Diseases, vol. 62, no. 4, pp. 327-333, 2019. doi: 10.1016/j.pcad.2019.08.004

[5] M. A. Espeland et al., "Effects of physical activity intervention on physical and cognitive function in sedentary adults with and without diabetes," The Journals of Gerontology: Series A, vol. 72, no. 6, pp. 861-866, 2017. doi: 10.1093/gerona/glw179

[6] A. M. Leiva et al., "Sedentary lifestyle is associated with metabolic and cardiovascular risk factors independent of physical activity,” Revista Médica de Chile, vol. 145, no. 4, pp. 458-467, 2017. doi:

10.4067/s0034-98872017000400006

[7] E. J. Martínez-López et al., “Association of low weekly physical activity and sedentary lifestyle with self-perceived health, pain, and well-being in a Spanish teenage population,” Science \& Sports, vol. 30, no. 6, pp. 342-351, 2015. doi: 10.1016/j.scispo.2015.04.007

[8] M. S. Tremblay et al., "New Canadian physical activity guidelines," Applied Physiology, Nutrition, and Metabolism, vol. 36, no. 1, pp. 36-46, 2011. doi: 10.1139/H11-009

[9] World Health Organization, "Information sheet: Global recommendations on physical activity for health 5-17 years old,” WHO, 2011.
[10] J. Mcneil et al., “Objectively - measured sleep and its association with adiposity and physical activity in a sample of Canadian children,” Journal of Sleep Research, vol. 24, no. 2, pp. 131-139, 2015. doi: 10.1111/jsr.12241

[11] F. M. Acosta et al., “Association of objectively measured physical activity with brown adipose tissue volume and activity in young adults," The Journal of Clinical Endocrinology \& Metabolism, vol. 104, no. 2, pp. 223-233, 2019. doi: 10.1210/jc.2018-01312

[12] C. Foster, J. B. Moore, C. R. Singletary, and J. A. Skelton, "Physical activity and family - based obesity treatment: a review of expert recommendations on physical activity in youth,” Clinical Obesity, vol. 8, no. 1, pp. 68-79, 2018. doi: 10.1111/cob.12230

[13] G. Roglic, "WHO Global report on diabetes: A summary," International Journal of Noncommunicable Diseases., vol. 1, no. 1, p. 3-8, 2016

[14] A. Thomas and L. Janusek, "Obesity prevention behaviors in Asian Indian adolescent girls: A Pilot Study,” Journal of Pediatric Nursing, vol. 42, pp. 9-15, 2018. doi: 10.1016/j.pedn.2018.05.007

[15] R. Sutherland et al., "A cluster randomised trial of an intervention to increase the implementation of physical activity practices in secondary schools: study protocol for scaling up the physical activity 4 everyone (PA4E1) program,” BMC Public Health, vol. 19, no. 1, p. 883, 2019. doi: 10.1186/s12889-019-6965-0

[16] L. Smith, S. Harvey, L. Savory, S. Fairclough, S. Kozub, and C. Kerr, "Physical activity levels and motivational responses of boys and girls: A comparison of direct instruction and tactical games models of games teaching in physical education,” European Physical Education Review, vol. 21, no. 1, pp. 93-113, 2015. doi: $10.1177 / 1356336$ X14555293

[17] C. Kerr et al., "Physical education contributes to total physical activity levels and predominantly in higher intensity physical activity categories,” European Physical Education Review, vol. 24, no. 2, pp. 152-164, 2018. doi: $10.1177 / 1356336$ X14555293

[18] H. Hawley-Hague, M. Horne, D. A. Skelton, and C. Todd, "Older adults' uptake and adherence to exercise classes: instructors' perspectives,” Journal of Aging and Physical Activity, vol. 24, no. 1, pp. 119-128, 2016. doi: 10.1123/japa.2014-0108

[19] C. S. Pawlowski, H. B. Andersen, J. Troelsen, and J. Schipperijn, "Children's physical activity behavior during school recess: A pilot study using GPS, accelerometer, participant observation, and go-along interview," PLoS One, vol. 11, no. 2, p. e0148786, 2016. doi: 10.1371/journal.pone.0148786

[20] T. Remmers, C. Thijs, D. Ettema, S. de Vries, M. Slingerland, and S. Kremers, "Critical hours and important environments: relationships between afterschool physical activity and the physical environment using GPS, GIS and accelerometers in 10-12-year-old children,” International Journal of Environmental Research and Public Health, vol. 16, no. 17, p. 3116, 2019. doi: 10.3390/ijerph16173116 
[21] M. B. Owen, W. B. Curry, C. Kerner, L. Newson, and S. J. Fairclough, "The effectiveness of school-based physical activity interventions for adolescent girls: A systematic review and meta-analysis," Preventive Medicine, vol. 105, pp. 237-249, 2017. doi: 10.1016/j.ypmed.2017.09.018

[22] E. E. Dooley, N. M. Golaszewski, and J. B. Bartholomew, "Estimating accuracy at exercise intensities: a comparative study of self-monitoring heart rate and physical activity wearable devices,” JMIR mHealth uHealth, vol. 5, no. 3, p. e34, 2017. doi: 10.2196/mhealth.7043

[23] L. Nur, A. Suherman, and H. Subarjah, "The use of global positioning system (GPS) polars to determine motion intensity,” Journal of Engineering Science and Technology, vol. 14, no. 4, pp. 2132-2139, 2019.

[24] A. S. Gram, E.-M. Bladbjerg, J. S. Quist, M. B. Petersen, M. Rosenkilde, and B. Stallknecht, "Anti-inflammatory effects of active commuting and leisure time exercise in overweight and obese women and men: a randomized controlled trial,” Atherosclerosis, vol. 265, pp. 318-324, 2017. doi: 10.1016/j.atherosclerosis.2017.06.923

[25] A. Rokhayati, L. Nur, E. Elan, and G. Gandana, “Tactical approach to increase motivation for learning students on physical education teaching in primary schools," IOP Conference Series: Materials Science and Engineering 180, 2017. doi: 10.1088/1757-899X/180/1/012259

[26] L. Nur, P. M. Setiadi, Y. Kusdinar, and A. A. Malik, "Electronic rubric for motivation in physical education," Journal of Physics: Conference Series 1318, 2019. doi: 10.1088/1742-6596/1318/1/012129

[27] K. Diehl, A. K. Fuchs, K. Rathmann, and J. Hilger-Kolb, "Students' motivation for sport activity and participation in university sports: A mixed-methods study," BioMed Research International, vol. 2018, 2018. doi: 10.1155/2018/9524861

[28] D. Chatzopoulos, A. Drakou, M. Kotzamanidou, and H. Tsorbatzoudis, "Girls' soccer performance and motivation: games vs technique approach,” Perceptual and Motor Skills, vol. 103, no. 2, pp. 463-470, 2006. doi: 10.2466/pms.103.2.463-470

[29] S. Harvey, C. J. Cushion, H. M. Wegis, and A. N. Massa-Gonzalez, "Teaching games for understanding in American high-school soccer: A quantitative data analysis using the game performance assessment instrument," Physical Education and Sport Pedagogy, vol. 15, no. 1, pp. 29-54, 2010. doi: 10.1080/17408980902729354

[30] I. Mesquita, C. Farias, and P. Hastie, “The impact of a hybrid sport education-invasion games competence model soccer unit on students' decision making, skill execution and overall game performance," European Physical Education Review, vol. 18, no. 2, pp. 205-219, 2012. doi: 10.1177/1356336X12440027

[31] S. Gray and J. Sproule, "Developing pupils’ performance in team invasion games," Physical Education and Sport Pedagogy, vol. 16, no. 1, pp. 15-32, 2011. doi: $10.1080 / 17408980903535792$

[32] S. Nathan and J. Haynes, "A move to an innovative games teaching model: Style E Tactical (SET),” Asia-Pacific Journal of Health, Sport and Physical Education, vol. 4, no. 3, pp. 287-302, 2013. doi: 10.1080/17408980903535792

[33] K. Jayantilal and N. O’Leary, “(Reinforcing) factors influencing a physical education teacher's use of the direct instruction model teaching games,” European Physical Education Review, vol. 23, no. 4, pp. 392-411, 2017. doi: $10.1177 / 1356336 X 16652081$

[34] C. B. Corbin, "Physical Activity for Everyone: About Promoting Lifelong Physical Activity,” Journal of Teaching in Physical Education, vol. 21, pp. 128-144, 2002. doi: 10.1123/jtpe.21.2.128

[35] L. Foweather, Z. Knowles, N. D. Ridgers, M. V O’Dwyer, J. D. Foulkes, and G. Stratton, "Fundamental movement skills in relation to weekday and weekend physical activity in preschool children," Journal of Science and Medicine in Sport, vol. 18, no. 6, pp. 691-696, 2015. doi: 10.1016/j.jsams.2014.09.014

[36] P. E. Yeatts, S. B. Martin, and T. A. Petrie, "Physical fitness as a moderator of neuroticism and depression in adolescent boys and girls," Personality and Individual Differences, vol. 114, pp. 30-35, 2017. doi: 10.1016/j.paid.2017.03.040

[37] E. L. Budd, A. McQueen, A. A. Eyler, D. Haire-Joshu, W. F. Auslander, and R. C. Brownson, "The role of physical activity enjoyment in the pathways from the social and physical environments to physical activity of early adolescent girls,” Preventive Medicine, vol. 111, no. July 2017, pp. 6-13, 2018. doi: 10.1016/j.ypmed.2018.02.015

[38] S. Lotfi, I. Elmoutaraji, and M. Talbi, "Effect of physical exercise and gender on information processing and choice reaction time of university students,” International Journal of Human Movement and Sports Sciences, vol. 8, no. 1, pp. 37-42, 2020. doi: 10.13189/saj.2020.080105

[39] O. Lutsenko, G. Lucenko, M. Khrolenko, and O. Mehem, "Defining the conditions of forming students motivation to movement activity," International Journal of Human Movement and Sports Sciences, vol. 8, no. 4, pp. 117-123, 2020. doi:10.13189/saj.2020.080403 